\title{
Investigation into the Possible Risk Effects Associated with Drug and Alcohol-induced Gastrointestinal Ulcer in Wistar Albino Rats
}

\author{
Oladayo E. Apalowo ${ }^{1}$, Oladayo J. Areola ${ }^{2}$, Gbenga S. Ogunleye ${ }^{1}$ \\ Ayodeji S. Odukoya ${ }^{3}$ and Olusegun O. Babalola ${ }^{1 *}$
}

${ }^{1}$ Department of Biochemistry and Molecular Biology, Obafemi Awolowo University, Ile-Ife, Nigeria. ${ }^{2}$ Department of Medical Biochemistry, Obafemi Awolowo University, Ile-Ife, Nigeria. ${ }^{3}$ Department of Anatomy and Cell Biology, Obafemi Awolowo University, Ile-Ife, Nigeria.

Authors' contributions

This work was carried out in collaboration among all authors. Authors OEA and OOB designed the study, performed the statistical analysis, wrote the protocol and wrote the first draft of the manuscript.

Authors OJA and ASO managed the analyses of the study. Author GSO managed the literature searches. All authors read and approved the final manuscript.

Article Information

DOI: 10.9734/ARRB/2019/v32i330085

Editor(s):

(1) Dr. Layla Omran Elmajdoub, Department of Zoology, Misurata University, Misurata, Libya (2) Dr. Tunira Bhadauria, Professor, Department of Zoology, Feroze Gandhi Post Graduate College, Kanpur University, U .P. India.

(1) Syed Umer Jan, University of Balochistan, Pakistan. (2) Michael Bordonaro, Geisinger Commonwealth School of Medicine, USA Complete Peer review History: http://www.sdiarticle3.com/review-history/49790

Original Research Article

Received 28 April 2019

Accepted 01 July 2019

Published 09 July 2019

\begin{abstract}
Aim: The study investigated the possible risks associated with gastrointestinal ulcer disease by evaluating the biochemical response of three body organs; heart, kidney and liver, in gastric ulcerated rats.

Methodology: Twenty male wistar albino rats were used in the study. Gastric ulcer was induced in rats with single oral dose of $400 \mathrm{mg} / \mathrm{kg}$ body weight (b.w.) aspirin, $80 \mathrm{mg} / \mathrm{kg}$ b.w. indomethacin and $5 \mathrm{ml} / \mathrm{kg}$ b.w. acidified ethanol $(40: 60 \mathrm{v} / \mathrm{v})$. Blood samples were collected into heparinized bottle and centrifuged at $4000 \mathrm{rpm}$ for 10 mins to obtain the plasma. Gastric tissue, liver, kidney and heart were also collected.

Results: Oral administration of $400 \mathrm{mg} / \mathrm{kg} \mathrm{b.w.} \mathrm{aspirin,} 80 \mathrm{mg} / \mathrm{kg}$ b.w. indomethacin and $5 \mathrm{ml} / \mathrm{kg}$ b.w. acidified ethanol caused a remarkable increase in ulcer index. There was observed a significant
\end{abstract}


$(\mathrm{p}<0.05)$ reduction in AST and ALT activities in gastric ulceration caused by aspirin (Asp), with no significant $(p<0.05)$ change in total protein (TP) concentration, lactate dehydrogenase and creatine kinase activity. However, there was increase in creatinine and urea concentration. Acidified ethanol and Indomethacin-induced ulcerated rats showed significant $(p<0.05)$ reduction in all other parameters except ALT and lactate dehydrogenase activities which did not show any significant $(p<0.05)$ change. There was also observed a significant $(p<0.05)$ increase in creatine kinase activity in indomethacin-induced ulcerated rats.

Conclusion: Overall, the result indicates a link between gastric ulcer and organ toxicity. The use of NSAIDs above the therapeutic doses in the treatment of pains and related illness as well as excess consumption of alcohol is shown to negatively impact the stomach and cause serious damage to different body organs of wistar rats.

Keywords: Organ toxicity; gastric ulcer; hepatotoxicity; nephrotoxicity; NSAID.

\section{INTRODUCTION}

Non-steroidal anti-inflammatory drugs (NSAIDs) are widely consumed medications worldwide for their use in the alleviation of rheumatism and osteoarthritis [1,2]. However, NSAIDs are more than just pain relievers. They have been used to reduce inflammation and lower fevers. Low dose aspirin (LDA, $\leq 325 \mathrm{mg}$ daily) has been used in the treatment of cardiovascular diseases as it plays an essential role as an antithrombotic agent to prevent cardiovascular events [3]. Consequently, NSAIDs have been reported to cause local injury on contact with gastric tissues as well as inhibiting gastrointestinal (Gl) mucosal COX activity, leading to Gl toxicity and nephropathy. Gl toxicity associated with the use of NSAIDs can range from mild dyspepsia to severe complications that lead to hospitalization and even death [4]. Gastric ulcers are gastrointestinal diseases observed as a disruption or cut in the mucosal surface of $5 \mathrm{~mm}$ or more which penetrate into the submucosa. An erosion is said to occur if mucosal damage is smaller than $5 \mathrm{~mm}$ in size or which involves mucosal disruption only $[5,6]$. Although helicobacter pylori has been identified as the major cause of gastric ulcer, large use of nonsteroidal anti-inflammatory drugs (NSAIDs), increase in alcohol consumption and life style increase the risk of the disease [7]. The incidence of serious gastrointestinal complications has been estimated as 1 case per 1,000 persons in a year, with a fatality rate around $5-10 \%$. This incidence was around two and four times higher for users of aspirin and non-aspirin NSAIDs, respectively [4].

It remains still unclear whether GI ulcer disease is independently associated with specific chronic medical illnesses. Therefore, the study investigated the possible risks associated with GI ulcer disease by evaluating the biochemical response of three body organs; heart, kidney and liver, in gastric ulcerated rats.

\section{MATERIALS AND METHODS}

\subsection{Methods}

\subsubsection{Chemicals and drugs}

Alanine aminotransferase, aspartate aminotransferase, total protein, urea, creatinine, lactate dehydrogenase and creatine kinase diagnostic kits were obtained from Randox Laboratories Ltd, United Kingdom. Ethanol, $\mathrm{HCl}$, $\mathrm{K}_{2} \mathrm{HPO}_{4}, \mathrm{KH}_{2} \mathrm{PO}_{4}$ were obtained from SigmaAldrich (USA). Aspirin and indomethacin were procured from Tuyil Pharmaceutical Industries Limited (Nigeria) and Jiangxi Xier Kangtai Pharmaceuticals (China) respectively. All reagents were prepared and stored at $4{ }^{\circ} \mathrm{C}$.

\subsubsection{Experimental animals}

Twenty male wistar albino rats (150-250 g, 14 weeks old) were used in the study and were obtained from Faculty of Pharmacy, Obafemi Awolowo University, Osun State, Nigeria. The animals were maintained under standard laboratory condition (12-h light/dark cycle). They were fed with standard pellet diet and water ad libitum. The animals were acclimatized to laboratory condition for two weeks prior to experimentation. The principle of laboratory animal care (National Institute of Health Publication No. 85-23) guidelines and procedures were followed in the study $(\mathrm{NIH}$ publication revised, 1985).

\subsection{Animal Grouping and Gastric Ulcer Induction}

Animals were divided into four groups, each depicting the mode of ulcer induction and each 
group consisted of five animals; Group 1 control, group 2 - aspirin, group 3 indomethacin and group 4 - acidified ethanol. Animals were fasted overnight to ensure that the stomach was completely emptied. Thereafter, gastric ulcer was induced in the experimental animals with single oral dose of aspirin at 400 $\mathrm{mg} / \mathrm{kg}$ body weight (b.w.) for group 2; $80 \mathrm{mg} / \mathrm{kg}$ b.w. indomethacin for group 3 and $5 \mathrm{ml} / \mathrm{kg} \mathrm{b.w.}$ acidified ethanol $(40: 60 \mathrm{v} / \mathrm{v})$ while the control group received only water. The animals in group 2 and group 3 were left for $6 \mathrm{hrs}$ while group 4 animals were left for $4 \mathrm{hrs}$ to allow complete digestion of the drug. Blood samples were collected into heparinized bottle and centrifuged at $4000 \mathrm{rpm}$ for 10 mins to obtain the plasma. Likewise, gastric tissue, kidney, liver and heart were removed and prepared by homogenizing in $10 \%(\mathrm{w} / \mathrm{v})$ separately in phosphate buffer solution ( $\mathrm{pH}$ 7.4) using Potter- Elvejhem glass homogenizer. The homogenates were centrifuged at $4000 \mathrm{rpm}$ for $15 \mathrm{~min}$ and the supernatant was collected. These served as a source for the assessment of hepatic, nephritic and cardiac marker enzymes.

\subsection{Biochemical Analysis}

Total protein concentration, alanine aminotransferase, aspartate aminotransferase, creatinine, urea, lactate dehydrogenase and creatine kinase concentrations were estimated using standard Randox diagnostic kits.

\subsection{Ulcer Index Determination}

The Ulcer index (UI) was determined using a measuring scale to measure the ulcerated area as reported by Choudhary et al. [8]. The ulcerated area and the total mucosal area were determined.

$$
\text { Ulcer index }=10 / X
$$

\section{Where}

$\mathrm{X}=$ total mucosal surface/ total ulcerated area

\subsection{Statistical Analysis}

Data presented as mean \pm SD. Relationships between groups were carried out using one way analysis of variance (ANOVA) followed by Tukey-Kramer multiple comparisons test using Graphpad Prism. A probability level of less than 0.05 ( $p<0.05$ ) was accepted as statistically significant.

\section{RESULTS}

Morphological assessment of aspirin (Asp) and indomethacin-induced (IND) ulcerated gastric tissues showed deep perforations, inflammation, loss of mucus with larger patches and excessive bleeding (hemorrhagic lesions) observed in indomethacin group (IND). However, acidified ethanol group (ACEtH) resulted in gastric tissue necrosis Fig. 1.

The effect of Aspirin (Asp), indomethacin (IND) and acidified ethanol (ACEtH) on gastric ulcer index are shown in Fig. 2. Oral administration of $400 \mathrm{mg} / \mathrm{kg}$ b.w. aspirin, $80 \mathrm{mg} / \mathrm{kg} \mathrm{b.w.}$ indomethacin and $5 \mathrm{ml} / \mathrm{kg}$ b.w. acidified ethanol caused a remarkable increase in ulcer index as compared to the control.

Fig. 3 shows the changes in total protein concentration, aspartate aminotransferase (AST) and alanine aminotransferase (ALT) activities in ulcerated rats. There was observed a significant $(p<0.05)$ reduction in AST and ALT activities in gastric ulceration caused by aspirin (Asp), with no significant $(p<0.05)$ change in total protein (TP) concentration when compared to the control. However, total protein concentration as well as AST activity showed a significant $(p<0.05)$ reduction in gastric ulceration caused by indomethacin (IND) and acidified ethanol $(\mathrm{ACE} H \mathrm{H})$ in rats. While there was further reduction in ALT activity in indomethacin-induced gastric ulceration (IND), no significant $(p<0.05)$ difference was observed in ALT activity in gastric ulceration caused by acidified ethanol (ACEtH) when compared to the control.

Changes in creatinine and urea concentration in ulcerated rats are shown in Fig. 4. Creatinine level showed a significant $(p<0.05)$ increase while urea level showed no significant $(p<0.05)$ difference in gastric ulceration caused by aspirin (Asp) when compared to the control. However, creatinine and urea concentrations showed a significant $(p<0.05)$ decrease in gastric ulceration caused by indomethacin (IND) and acidified ethanol $(\mathrm{ACEtH})$ in rats, with the latter resulting to a more remarkable decrease in the level of creatinine when compared to the control.

Creatine kinase and lactate dehydrogenase activities in gastric ulcerated rats are shown in Fig. 5. Gastric ulceration caused by aspirin (Asp) and indomethacin (IND) showed no significant $(p<0.05)$ difference in the activity of lactate dehydrogenase. However, a significant increase 
in creatine kinase activity was observed in gastric ulceration caused by indomethacin (IND) while aspirin-induced gastric ulcerated rats (Asp) showed no observable change in the activity of the enzyme. Acidified ethanol-induced gastric ulcerated rats (ACEtH) however showed a significant $(p<0.05)$ decrease in creatine kinase and lactate dehydrogenase activities.

\section{DISCUSSION}

The gastrointestinal tract (GIT) acts as an interface between the environment and the internal medium of an organism. It functions mainly in food digestion and absorption of nutrients. Further investigations have revealed other functions of the GIT to include immune defense, excretion of metabolic by-products and detoxification, secretory and regulatory functions [9]. Consequently, toxins ingested during food intake as well as some drugs, may contribute to damaging the gastric mucosa [10,11]. Alcohol and NSAIDs have been reported to be the second most important cause of gastric injury after $H$. pylori [12]. Evidence from wellestablished gastric mucosa injury in animal models suggests two notable mechanisms responsible for tissue damage. The first

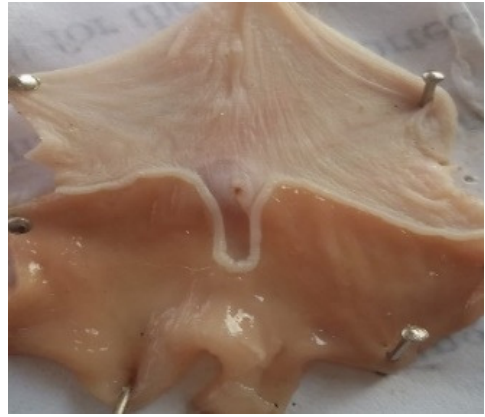

(a)

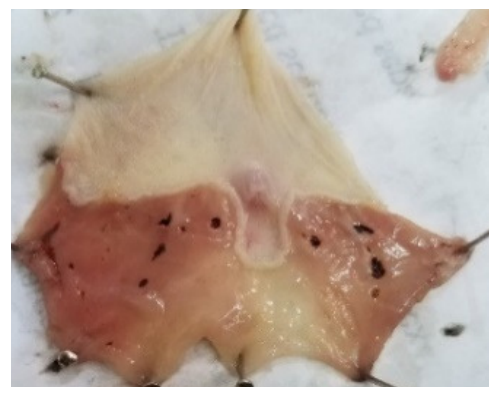

(c) mechanism proposes a direct toxic contact on the gastric mucosa which leads to the uncoupling of electron transport chain, resulting in the breakdown of ion channels and permeability of intracellular junctions [13]. The effect of this is redox imbalance leading to the generation of excess free radicals and consequently gastric ulceration [14,15]. Ethanol increases free radicals concentration and decreases antioxidant levels. This process eventually results to oxidative stress $[16,17]$ and might account for the ulcer index observed in the result. The second mechanism was proposed to be due to limitation of gastric microcirculatory blood flow which is crucial to proliferation and mucus secretion in gastric tissue through decreased levels of gastroprotective prostaglandin E2 [18]. This subsequently leads to endothelial dysfunction and autonomic dysregulation which may result in oxidant/ antioxidant imbalance leading to oxidative stress $[9,19]$. Aspirin irreversibly bind to cyclooxygenase enzymes (COX-1 and COX-2) and in such case, leads to their inhibition and inactivity [19] as observed in this study. Studies have associated COX-1 with the protection of the mucus lipid bilayer of the mucosa through the upregulation of prostaglandin E2 (PGE2) and prostacyclins $[20,21]$.

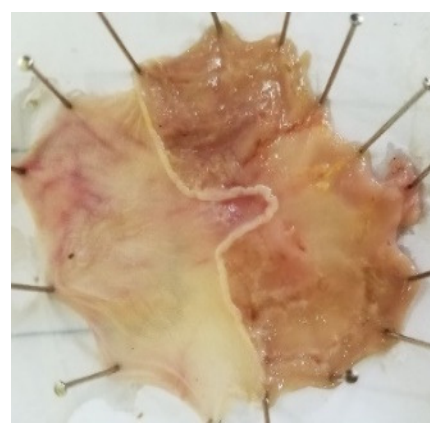

(b)

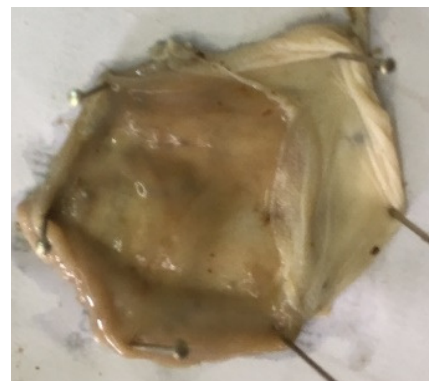

(d)

Fig. 1. Morphological assessment of gastric mucosal injury induced by aspirin (b), indomethacin (c) and acidified ethanol (d) in rats; control (a) 


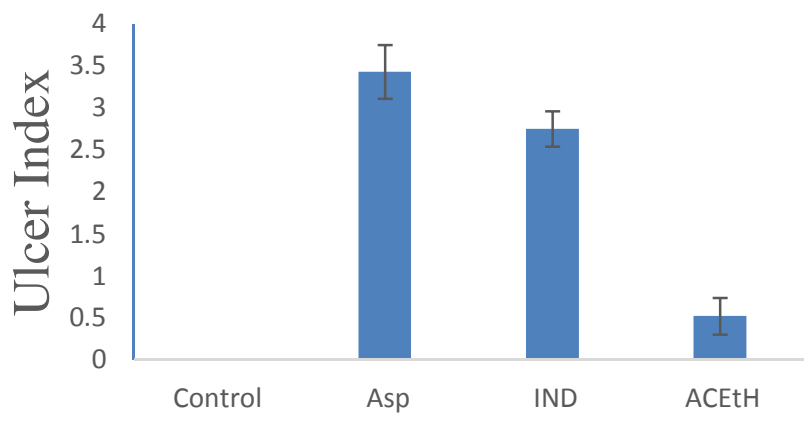

Fig. 2. Effects of aspirin (asp), indomethacin (ind) and acidified ethanol (aceth) on ulcer index Bars represent the degree of gastric ulceration induced in tats by $400 \mathrm{mg} / \mathrm{kg} \mathrm{b.w}$. aspirin, $80 \mathrm{mg} / \mathrm{kg} \mathrm{b.w}$. indomethacin and $5 \mathrm{ml} / \mathrm{kg}$ b.w. HCl/Ethanol. Data expressed as mean $\pm S D$

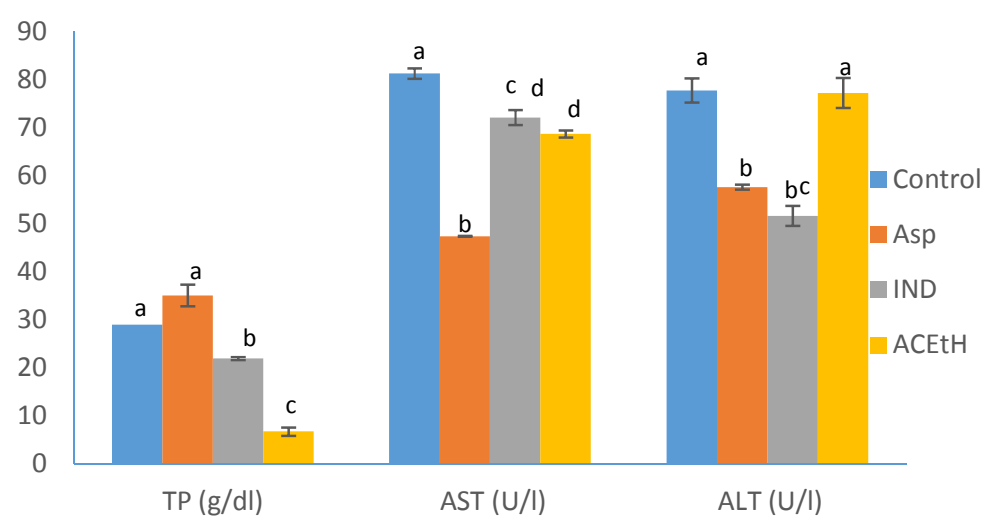

Fig. 3. Effects of $400 \mathrm{mg} / \mathrm{kg}$ b.w. aspirin (Asp), $80 \mathrm{mg} / \mathrm{kg} \mathrm{b.w.} \mathrm{indomethacin} \mathrm{(IND)} \mathrm{and} 5 \mathrm{ml} / \mathrm{kg}$ b.w. acidified ethanol (ACEtH) on total protein (TP), aspartate aminotransferase (AST) and alanine aminotransferase (ALT) levels in ulcerated rats $(n=5)$

Data expressed as mean $\pm S D$. Bars with different superscripts for each parameter are significantly different $(p<0.05)$

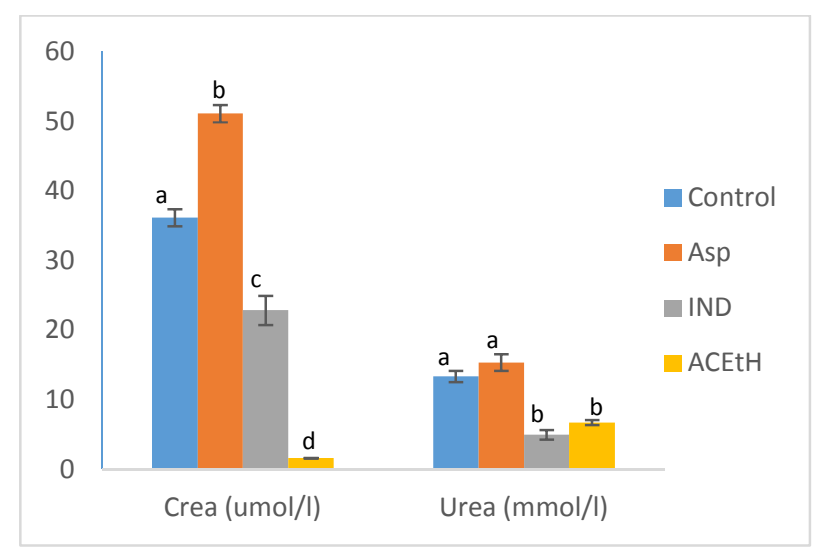

Fig. 4. Effects of $400 \mathrm{mg} / \mathrm{kg}$ b.w. aspirin (Asp), $80 \mathrm{mg} / \mathrm{kg} \mathrm{b.w.} \mathrm{indomethacin} \mathrm{(IND)} \mathrm{and} 5 \mathrm{ml} / \mathrm{kg}$ b.w. acidified ethanol (ACEtH) on creatinine (Crea) and urea levels in ulcerated rats $(n=5)$ Data expressed as mean $\pm S D$. Bars with different superscripts for each parameter are significantly different $(p<0.05)$ 


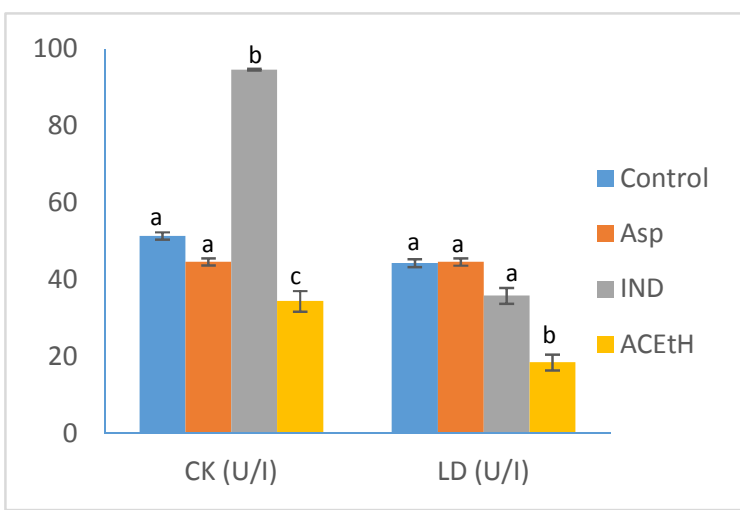

Fig. 5. Effects of $400 \mathrm{mg} / \mathrm{kg}$ b.w. aspirin (Asp), $80 \mathrm{mg} / \mathrm{kg} \mathrm{b.w.} \mathrm{indomethacin} \mathrm{(IND)} \mathrm{and} 5 \mathrm{ml} / \mathrm{kg}$ b.w. acidified ethanol (ACEtH) on creatine kinase (CK) and lactate dehydrogenase (LD) levels in ulcerated rats $(n=5)$

Data expressed as mean $\pm S D$. Bars with different superscripts for each parameter are significantly different $(p<0.05)$

Redox balance is a major homeostatic parameter which serves as a regulatory factor for the metabolic functions of the whole organism and also the GIT [22]. Drugs and xenobiotics detoxification in the liver by drug metabolizing enzymes (DMEs) is a major factor in the acquisition of homeostasis [23]. Hence, alteration in the homeostatic status (redox imbalance) causes a change in dynamic equilibrium of metabolism by generating reactive oxygen species, thereby causing oxidative stress and subsequently organ malfunctions [24]. Nephrotoxicity and hepatotoxicity have been reported to be mostly due to the overproduction of reactive oxygen species. As reported by Oloyede and Sunmonu [25], the decrease in the specific activity of liver AST and ALT and significant increase in serum activities of these two enzymes suggest the possibility of a leakage of the enzymes from the liver to the serum which may be interpreted to mean liver damage. These are highly specific and sensitive biomarkers to detect hepatotoxicity. The remarkable decrease in liver AST and ALT levels in acidified ethanol, aspirin and indomethacin-induced gastric ulcerated rats may be interpreted to mean liver damage. In addition, Luedde et al. [26] reported a link in progression of liver damage to the action of kupffer cells through the production of proinflammatory mediators, cytokines and chemokines, mediation of cytotoxicity by degrading the extracellular matrix and promoting cell adhesion and leukocyte infiltration, the latter having been reported to be increased during gastrointestinal damage and ulcer [27]. This may therefore suggests a link between the transaminase enzymes and inflammatory neutrophilic polymorphonuclear leukocytes (neutrophil infiltration) as the former have been reported to assist in differential diagnosis of cardiac diseases [25].

Nephrotoxicity has been identified by several metabolic disorders including increase in blood or kidney accumulation of creatinine and urea, a breakdown product of muscle creatine phosphate and waste product of liver protein breakdown respectively $[28,29]$. Urea accumulation in the inner medullary during antidiuretic hormone (ADH)-induced antidiuresis is known to be critical to the process of urinary concentration. However, NSAIDs generally cause alterations in renal function through the inhibition of vasodilator prostaglandin synthesis from arachidonic acid leading to vasoconstriction and a decrease in glomerular capillary pressure, resulting in a prompt decline in glomerular filtration rate [30]. This form of renal failure, characterized by a build-up in creatinine and urea level in the kidney is often rapid as observed in the aspirin-induced gastric ulcerated rats [31,32]. This is in agreement with the hypothesis [33] that aspirinlike drugs exert their various pharmacological effects via inhibition of prostaglandin biosynthesis and in part, due to its irreversible inhibitory action while indomethacin showed no inhibition, except a slight decline in the metabolites level. Hence, the role of aspirin in de-epithelialization and nephropathy may be linked via the same mechanism of prostaglandin synthesis inhibition. As observed in indomethacin and acidified ethanol-induced gastric ulcerated rats, decrease in the level of urea and creatinine may be due to the action of their active metabolites, such as acetaldehyde, in the case of ethanol which can also be connected with redox 
imbalance consequently leading to kidney damage [34].

Furthermore, predisposing conditions for acute tubular necrosis (ATN) during renal failure has been reported to include congestive heart failure. Since renal function has been observed to be increasingly dependent on renal prostaglandin synthesis (particularly PGI 2 and PGE 2) in certain conditions such as underlying glomerular disease and reduced renal perfusion, hence, it has been suggested that ATN may be associated with heart failure, due to gastrointestinal or renal salt and water loss [31]. Results from the study showed that there was an increase in creatine kinase activity of indomethacin-induced gastric ulcerated rats while no significant change was observed for aspirin-induced ulcerated rats. Creatine kinase activity has been observed to increase during myocardial injury as it is considerably more specific for myocardial damage. Lactate dehydrogenase is a well-known biomarker for cerebrovascular dysfunctions and muscular dystrophy [35]. Aspirin has been used for the treatment of various heart diseases and as such, its regulatory effect on creatine kinase and lactate dehydrogenase might have been justified by regulating the level of these enzymes. However, further decrease in these enzymes was observed in acidified ethanol-induced ulcerated rats which may likely indicate an association with kidney related stress or disease.

\section{CONCLUSION}

Generally, the result has shown a link between gastric ulcer and organ toxicity in wistar rats. The use of NSAIDs above the therapeutic doses in the treatment of pains and related illness as well as excess consumption of alcohol may negatively impact mucosal integrity and in turn cause serious damage to other organs.

\section{ETHICAL APPROVAL}

As per international standard written ethical approval has been collected and preserved by the author(s).

\section{COMPETING INTERESTS}

Authors have declared that no competing interests exist.

\section{REFERENCES}

1. Pal C, Bindu S, Dey S, Alam A, Goyal M, lqbal M. Gallic acid prevents nonsteroidal anti-inflammatory drug-induced gastropathy in rat by blocking oxidative stress and apoptosis. Free Radic Biol Med. 2010;49:258-267.

2. Ineu RP, Pereira ME, Aschner $M$, Nogeueira CW, Zeni G, Rocha JB. Diphenyl diselenide reverses gastric lesions in rats: Involvement of oxidative stress. Food Chem Toxicol. 2008;46:30239.

3. Guillermo G, Carlos S, Angel L. Aspirin and omeprazole for secondary prevention of cardiovascular disease in patients at risk for aspirin-associated gastric ulcers. Expert Rev Clin Pharmacol. 2017;10(8):789-797.

4. Rodríguez G, Hernández-Díaz S. Risk of uncomplicated peptic ulcer among users of aspirin and nonaspirin nonsteroidal antiinflammatory drugs. Am J Epidemiol. 2004;159:23-31.

5. Malfertheiner P, Chan F, Mc Coll K. Peptic ulcer disease. Lancet. 2009;374:1449-61.

6. Kumar V, Abbas A, Fausto N. Robbin's basic pathology. Philadelphia. Elsevier Saunders; 2007.

7. Sabbineni J. A note on peptic ulcers; Research and reviews. J Pharmacogn Phytochem. 2016;4(1):47-53.

8. Choudhary MK, Bodakhe SH, Gupta SK. Assessment of the antiulcer potential of Moringa oleifera root-bark extract in rats. Journal of Acupuncture and Meridian Studies. 2013;6(4):214-220.

9. Cherkas A, Zarkovic N. 4-Hydroxynonenal in redox homeostasis of gastrointestinal mucosa: Implications for the stomach in health and diseases. Antioxidants. 2018;7(118):2-14.

10. Mentis A, Lehours $P$, Mégraud F. Epidemiology and diagnosis of Helicobacter pylori infection. Helicobacter. 2015;20(1):1-7.

11. Kanner J, Lapidot T. The stomach as a bioreactor: Dietary lipid peroxidation in the gastric fluid and the effects of plant-derived antioxidants. Free Radic. Biol. Med. 2001;31:1388-1395.

12. Lanas A, Chan F. Peptic ulcer disease. Lancet. 2017;390:613-624.

13. Somasundaram S, Hayllar H, Rafi S, Wrigglesworth $J$, Macpherson A, Bjarnason I. The biochemical basis of nonsteroidal anti-inflammatory drug-induced damage to the gastrointestinal tract: A review and a hypothesis. Scand J Gastroenterol. 1995;30:289-299.

14. Liu Y, Tian X, Gou L, Fu X, Li S, Lan N. Protective effect of $L$-citrulline against 
ethanol-induced gastric ulcer in rats. Environ Toxicol Pharmacol. 2012;34:2807.

15. Mota CS, Freitas RB, Athayde ML, Boligon $A A$, Augusti $P$, Somacal $S$. Effect of Vernonia cognata on oxidative damage induced by ethanol in rats. Hum Exp Toxicol. 2011;30:675-84.

16. Inas ZA, Abdallah-Hala $\mathrm{AH}$, Khattab $\mathrm{H}$, Gehan $\mathrm{HH}$. Gastroprotective effect of Cordia myxa L. fruit extract against indomethacin-induced gastric ulceration in rats. Life Sci J. 2011;8(3):433-445.

17. Lüllmann H, Mohr K, Ziegler A, Bieger D. Color atlas of pharmacology. $2^{\text {nd }} \mathrm{Ed}$. Thieme Stuttgart. New York. 2000;166.

18. Simon JP, Prince SE. Natural remedies for non-steroidal anti-inflammatory druginduced toxicity. J. Appl. Toxicol. 2017;37: 71-83.

19. Wallace J. NSAID gastropathy and enteropathy: Distinct pathogenesis likely necessitates distinct prevention strategies. Br J Pharmacol. 2015;165:67-74.

20. Ige JO, Tijani A. Gastroprotective effect of methanolic extract of Gomphrena celosioides on indomethacin induced gastric ulcer in Wistar albino rats. Int J Appl Basic Med Res. 2015;5(1):4145.

21. Halter F, Tarnawski A, Schmassmann A, Peskar B. Cyclooxygenase 2- implications on maintenance of gastric mucosal integrity and ulcer healing, controversial issues and perspectives. Gut. 2001;49: 443-453.

22. Pérez S, Taléns-Visconti R, Rius-Pérez S, Finamor I, Sastre J. Redox signaling in the gastrointestinal tract. Free Radic. Biol. Med. 2017;104:75-103.

23. Singh D, William C, Upadhyay G. Druginduced liver toxicity and prevention by herbal antioxidants: An overview. Frontiers in Physiology. 2016;6:1-18.

24. Sies H, Berndt C, Jones D. Oxidative stress. Annu. Rev. Biochem. 2017;86:715748.
25. Oloyede OB, Sunmonu TO. Decrease in activities of selected rat liver enzymes following consumption of chemical effluent. Appl. Sci. Environ. Manage. 2008;12(2): 95-100.

26. Luedde T, Kaplowitz N, Schwabe R. Cell death and cell death responses in liver disease: Mechanisms and clinical relevance. Gastroenterology. 2014;147(4): 765-83.

27. Bayir Y, Odabasoglu F, Cakir A, Aslan A, Svleyman $\mathrm{H}$, Halici $M$, et al. The inhibition of gastric mucosal lesion, oxidative stress and neutrophil-infiltration in rats by the lichen constituent diffractaic acid. Phytomedicine. 2006;13:584-590.

28. Agyigra IA, Ejiofor JI, Magaji MG. Acute and subchronic toxicity evaluation of methanol stem-bark extract of Ximenia americana Linn (Olacaceae) in Wistar rats. Bull Fac Pharm Cairo Univ. 2017;55(2): 263-267.

29. Carls AB, Edward EA. Fundamental of clinical chemistry. In: Teitz, Copyright by Saunders, An Imprint of Elsevier Inc; 2003.

30. Ejaz P, Bhojani K, Joshi V. NSAIDs and kidney. J Assoc Physicians India. 2004;52:632-40.

31. Aprioku JS, Uche FI. Renal effects of nonsteroidal anti inflammatory drugs in albino rats. Br J Pharm Res. 2013;3(3):314-325.

32. Fenton RA, Knepper MA. Urea and renal function in the $21^{\text {st }}$ Century: Insights from knockout mice. J Am Soc Nephrol. 2007;18:679-688.

33. Crook D, Collins A. Comparison of effects of aspirin and indomethacin on human platelet prostaglandin synthetase. Ann Rheum Dis. 1977;36:459-463.

34. Mukherjee S. Alcohol metabolism and generation of free radicals: A deep insight. Alcohol. 2014;2(1):1-5.

35. Ndem JI, David IK. Biochemical indices of cardaic function of albino wistar rats exposed to Hippocratea africana root bark extract. J Biotechnol Biochem. 2017;3(1): 101-106.

(0) 2019 Apalowo et al.; This is an Open Access article distributed under the terms of the Creative Commons Attribution License (http://creativecommons.org/licenses/by/4.0), which permits unrestricted use, distribution, and reproduction in any medium, provided the original work is properly cited.

Peer-review history:

The peer review history for this paper can be accessed here. http://www.sdiarticle3.com/review-history/49790 